\title{
A view from the bodies corporate. \\ 3. Ora Dental Group Ltd
}

F. Stuart-Wilson

STOP PRESS.
THIS INTERVIEW TOOK PLACE

PRIOR TO THE ACOUISITION OF

ORA DENTAL GROUP LTD BY

OASIS DENTAL CARE LTD.

Julian Perry does not strike one as being the sort of man that would set off a fire alarm deliberately when there was no fire. The fact that he did and the reason that he did comes out quite late in our discussion over coffee one bright morning in central London.

Julian Perry likes to talk about the Ora Dental Group and it quickly becomes apparent that he holds strong views about dentistry. The Ora Dental Group was established in 1999 but I am told quite quickly that the whole idea was three years in the planning. 'I set it up' announces Julian Perry, 'because I was fed up with seeing poor quality dentistry.' I realise that this is not going to be one of those interviews where I have to tease out what the subject really thinks.

He goes on to explain 'It's a bit of a mission with me. I think patients can too often be seen as income. I wanted to be able to provide affordable private care and

\footnotetext{
Name: Julian Perry

Title: Chief Executive Officer Company: Ora Dental Group Established: 1999

Head Office: London

Number of practices: 10 with one opening in November

Clinical profile: Private practice

Current turnover: $€ 6$ million

Website address: www.oradental.co.uk
}

'We now have 10

\section{practices including}

Selfridges in London's

\section{Oxford Street. A new}

\section{practice in Harrods is due}

\section{to open in November.'}

preventative care. The dentist's job isn't to find things to do, but to help patients not have things done.' Thus he sets out his preventive philosophy in a nutshell and we return to this theme several times during the course of the interview.

In the 1990s, Julian Perry had two practices in London; he then bought a body corporate licence which he describes as 'an outdated and archaic practice. Everyone seems to think we should be against deregulation to protect our licence but I think deregulation should happen. The deregulation of the bodies corporate licence is a good thing. If you get rid of that banner, it would open up the market positively.'
'We now have 10 practices including Selfridges in London's Oxford Street. A new practice in Harrods is due to open in November.'

'As a group we're looking at all markets. We are also doing a deal with Marks and Spencer and Superdrug - both pro-active

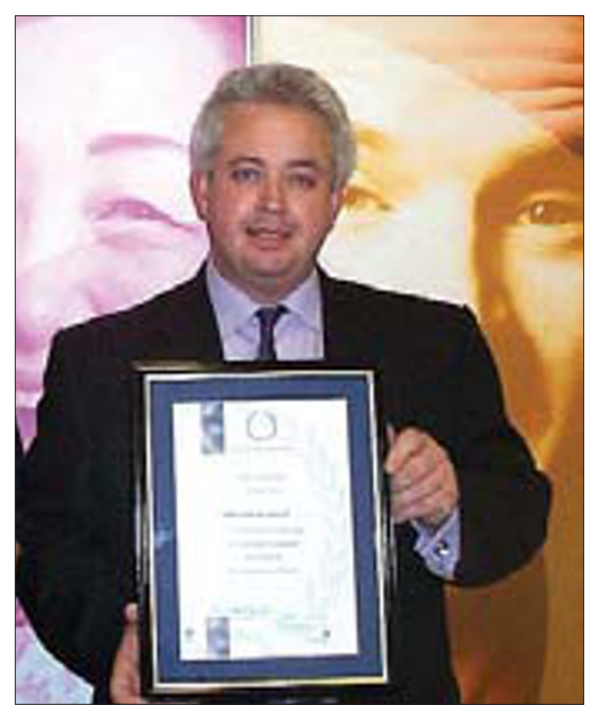

Julian Perry with Ora's liP Certificate 


\section{'Some practices are family practices, some are \\ cosmetic in focus. Our \\ practices are as diverse as \\ the patients we serve.'}

companies. Marks and Spencer is on the way up at the moment and has always had dentists in store for staff. We are looking at managing things like clinical governance for them.'

When I ask how this fits into the profile of the group, Julian Perry explains the range of operations. 'Some practices are family practices, some are cosmetic in focus. Our practices are as diverse as the patients we serve.'

He also tells me that four new practices are coming on board in the near future. 'All are within the M25 with the exception of Canterbury. Here we will have three practices, all with a different focus - they will cross-refer.'

Julian Perry also reveals that Ora is in discussions with Churchill Insurance, whom he describes as a "dynamic and staff-focused group. Churchill is looking at putting in

\section{'For a purely private group we still seem to spend a great deal of time talking about NHS funding.'}

occupational health services for its staff, including medical, dental and optical care.'

At this point he begins a counterpoint to his main theme of prevention by introducing his views on NHS funding which are forthright.

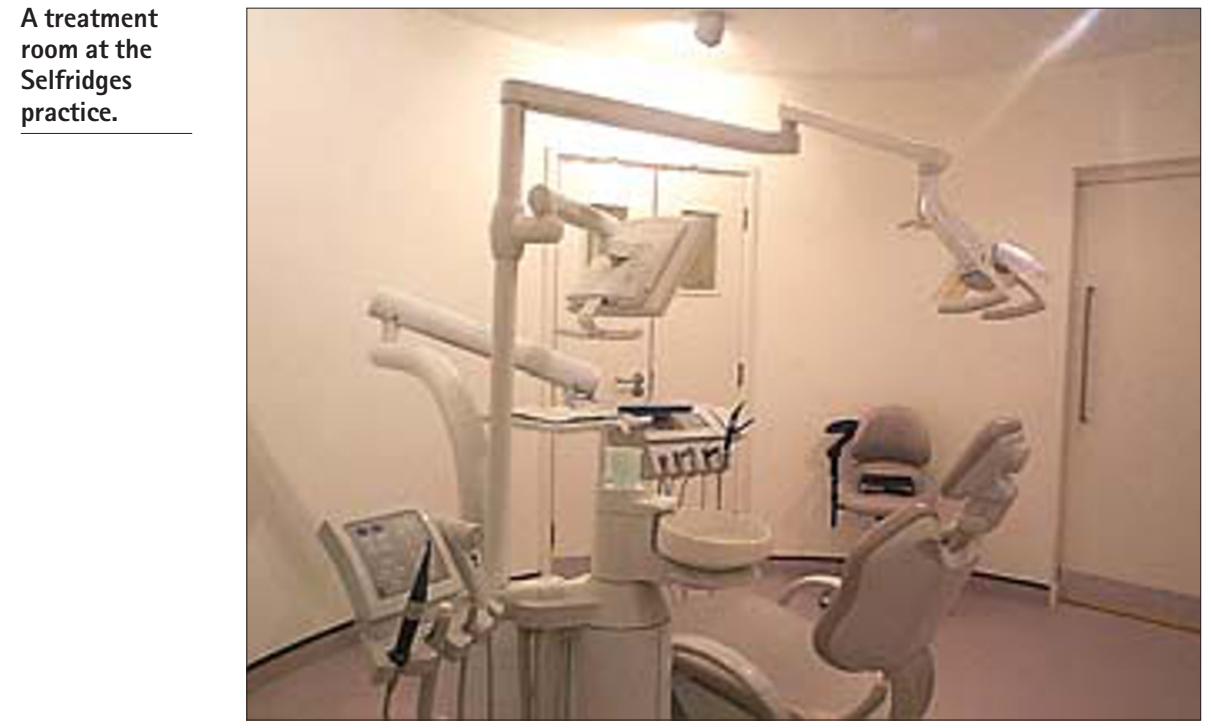

'Ora is a purely private group so we are not burdened by the NHS excuses.' He then reflects something which I find very interesting and that I have noticed other private practitioners do a great deal. 'For a purely private group we still seem to spend a great deal of time talking about NHS funding.' He goes on to explain what he means by the 'burden' he referred to earlier.

'One problem is that patients don't know what the NHS is. If patients compare dentists to GPs, the GP system is a filter to the hospital system.' He feels that it is 'wrong to use NHS fees as a benchmark. There has been an intentional privatisation of the market by successive governments. There's no other area at all where prices have gone down. The profession has been spineless over this. The idea of people investing in NHS practices is flawed. It's a poor return on investment.'

We turn to the acquisition of practices by Ora, and I ask Julian Perry what he looks for in a practice. The next figures that he quotes are interesting and give me an idea of the numbers of practitioners interested in selling their practices to a corporate.

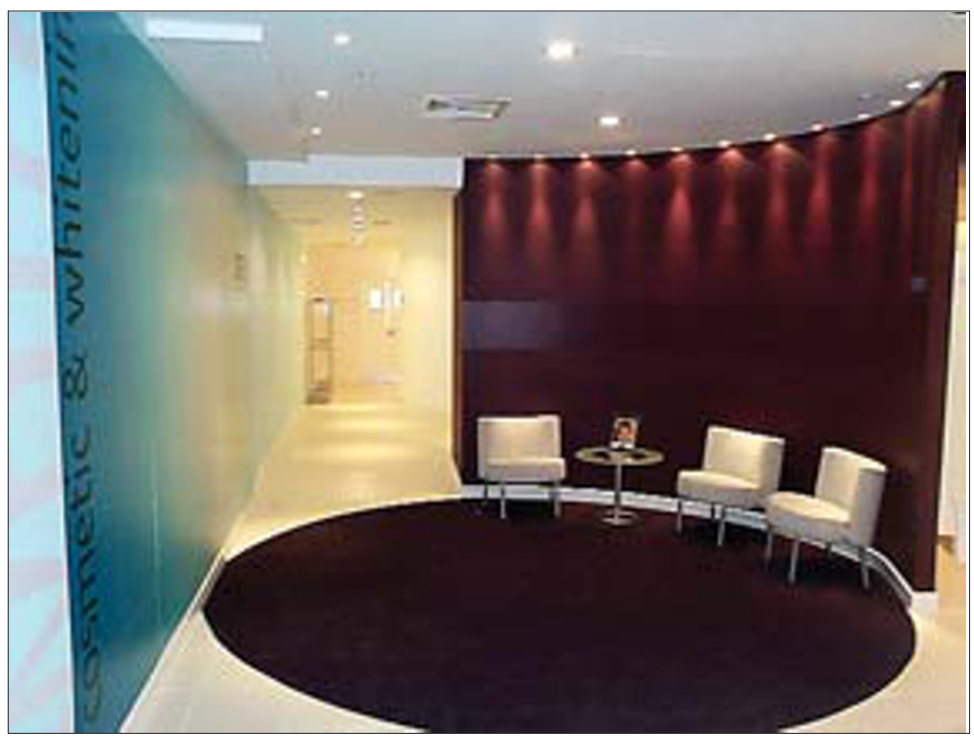

The reception area at the Selfridges practice
'Recently we looked at 350 practices but considered only three. We look for the quality of practice and the quality of practitioner.' Julian Perry sighs and says 'The number of times I have been told when I visit a practice 'This is probably the finest practice in London'. The ones that say that usually aren't.'

\section{'There has been an}

\section{intentional privatisation}

\section{of the market by}

\section{successive governments.'}

'BDA figures tell us that the average age of dental equipment is 14 years - I think from my experience that's optimistic.'

'What we look for in a practice? When we talk to the practitioner, part of the communication process is to find out where his or her ethical standards lie. There's no point in buying a practice which has had the cracks papered over just for sale.'

He is the first director to mention that part of the selection process as far as Ora is concerned involves a clinical audit, but this is the group that I am told was established partly out of a desire to raise the standards of care for patients.

'We ask to do a clinical audit to check out treatment planning, the quality of $\mathrm{x}$ rays, endo cases etc to try to get a feel for what the practice is doing.' He goes on to explain the reasoning behind this. 'No dentist can be jack of all trades - I think I'm the world's worst endodontist but I make sure that a patient is referred. You can be a good practitioner if you refer so that patients get the right level of care.'

He is aware that in some people's eyes 'corporates have a reputation for 'stack 'em high sell 'em cheap'. This is a group of private practitioners and Julian works in a 


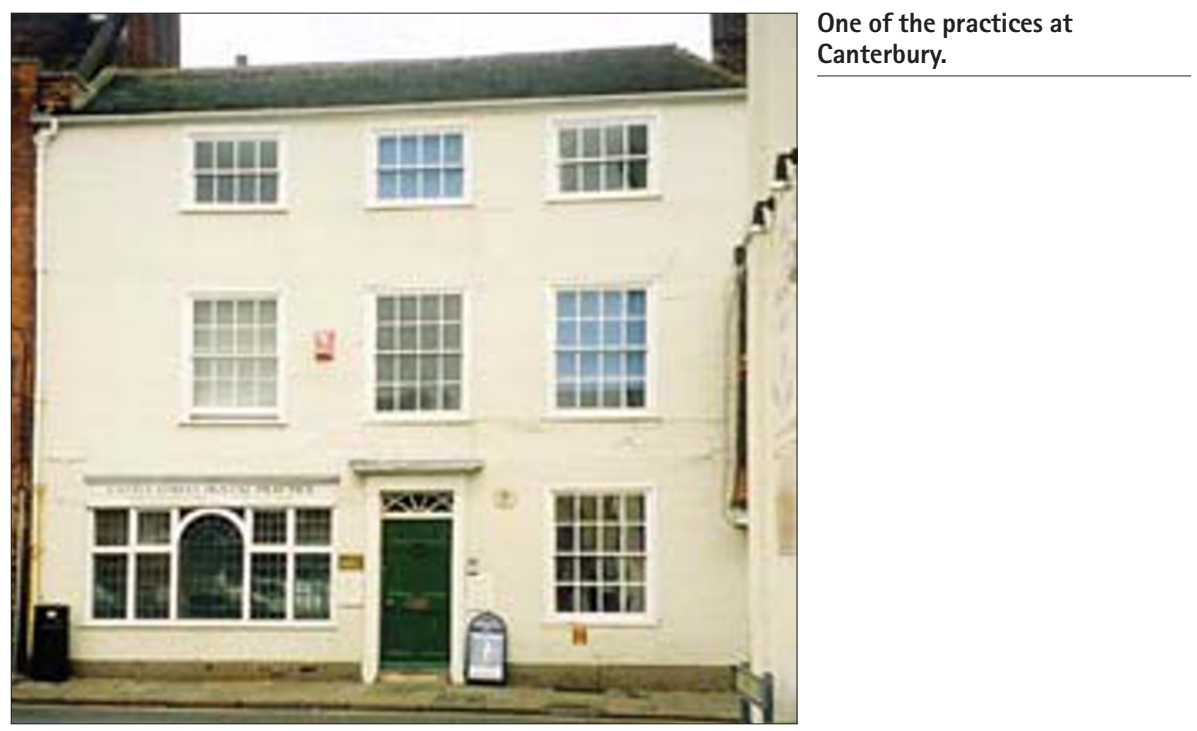

practice a few days a month "which cares about dentistry and quality of care.'

Those days in practice, as for Jitesh Patel of ADP, are important to Julian Perry. 'I'm not a desk jockey, I'm not out of touch. I do enough to keep my hand in so I can lead by example.'

So far as the quality he talks about is concerned, Julian Perry is a supporter of the OFT report, and sees it as a positive development. 'The OFT report was absolutely right. I was rung up by a journalist about it and when I said that to him he was dismayed at my reaction. He was expecting me to complain about it. But if you charge $£ 500$ for treatment such as a crown, and use a cheap lab, cheap materials and do it the same way that you would for the NHS, that's not acceptable. If you do a good job, use a good lab etcetera, then $£ 500$, well it’s value for money.'

'In the UK, the philosophy of the individual practitioner is very strong. We need to have the power to discipline dentists. But at the moment there's a debate about what legislation needs to be put in place to protect patients from body corporates. It's a load of rubbish. Every individual dentist is responsible for his or her own professional practice.'
'If, as I believe, the market is likely to be opened up to non-dentists, then there will be a gradual awakening of commercial reality. There are very few businesses which are lifetime careers which don't set budgets/targets for re-equipping. The nonunderstanding of accounts puts enormous

\section{'All our practices make} money. Of course we need new money to acquire new practices, so we're in a second round funding exercise.'

pressure on dentists. More help should be given to GDPs to understand business, from people who understand business and finance. For the most part, dentists are intelligent, university-trained people. It's not their fault that they don't understand, but they have to run a business to deliver healthcare.'

'They need to be supported, not beaten up. There is a huge amount of scope to help people.'

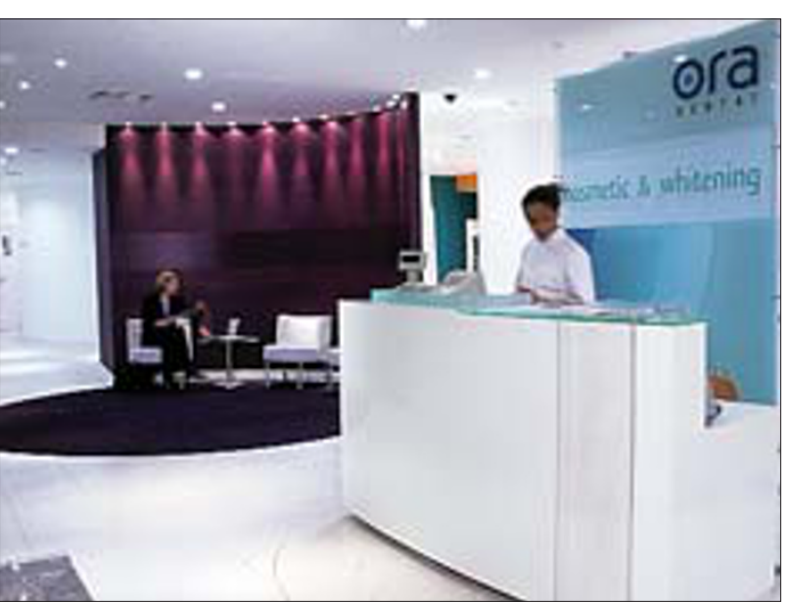

'In the future there will be more corporates about, but we won't be referring to them by that word. What we will have are practitioners taking investment from friends and family.'

\section{¿..it's no secret Ora bid to buy Dencare... The corporates all talk to each other all of the time.'}

At the time I am meeting Julian Perry, there have been reports of Ora's venture capitalists pulling out of the group. Julian Perry's response is swift and concise. 'All our practices make money. Of course we need new money to acquire new practices, so we're in a second round funding exercise.' He goes on,

'Consolidation of the corporate market will come about. After all it's no secret Ora bid to buy Dencare. We're not financially strapped. The corporates all talk to each other all of the time.'

I ask him about other developments that he sees over the next five years. In doing so we move back to issues around NHS funding. 'I don't think the PDS will make much difference unless it is appropriately funded. If dentists were paid properly to do work under the NHS then the NHS funding debate would disappear.'

Quality is another issue on the fiveyear agenda for Julian Perry. 'The demand for quality work will rise. As a society we are becoming more demanding - we want things on time, and we want things done well. The 1940s mentality of 'don't complain' has gone. There will be a lot more aspirational dentistry carried out.'

He returns to his theme of what dentists should be remunerated for. 'The drivers in dentistry are wrong for a healthcare profession. We've got to be proactive in prevention. Some practitioners are confident enough to charge their hourly rate for advice, education, diet control etcetera, but many don't charge for this.'

\section{'If dentists were paid} properly to do work under the NHS then the NHS funding debate would disappear.'

We move on to the subject of PCDs. 'Anything that brings the profession up is good. Nurses need better recognition. With therapists the problem will be to penetrate an associate-based profession, and to get them to refer.' So far as Julian is 


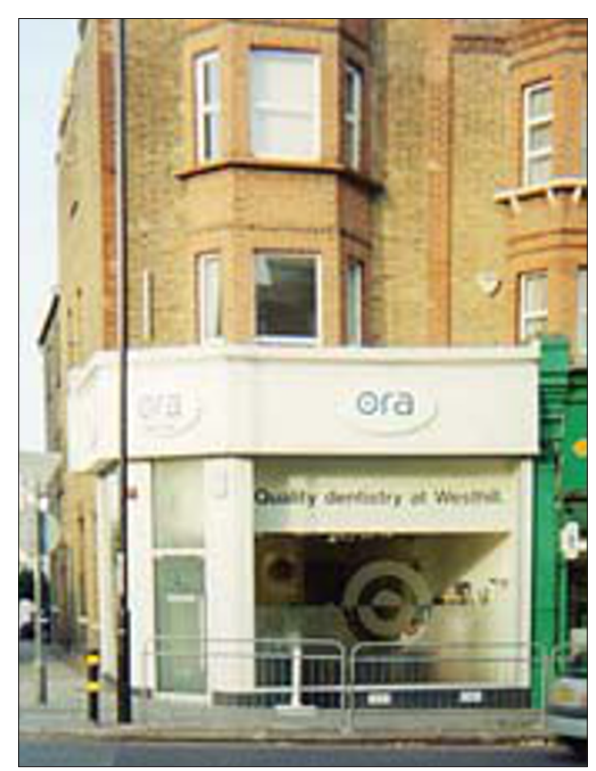

The Westhill practice.

concerned 'they certainly have a place in a preventative, customer-focused practice. Associates are solopsistic by nature - they tend to refer only difficult patients.'

And hygienists? 'There is a serious shortage of hygienists. This will drive up the hourly rate which will put pressure on patients to pay more. We could lead ourselves into a backward step - dentists will do the work themselves and they're not good at it!' If the current trends continue, Julian Perry believes that 'only expensive practices will be able to afford them.'

'Only 70 hygienists are trained at the Eastman - why don't they train more? Ora considered sponsoring some more hygienist training, but the people we approached wanted too much from us.'

Despite his comments about business and finance training Julian Perry does not foresee changes in undergraduate training. 'Birmingham has the same business training as it did 20 years ago when I was an undergraduate. Dental schools should be teaching people to be fiscally aware.'

'However most new graduates won't want to own practices. This will be good news when dentists are salaried.' I ask him what he means by this, and the answer is an echo of what many directors have told me.

'With associates, the percentage issue will be tackled over the next 10 years. There is a natural reluctance to deal with this. There will be a rude awakening for associates; most have no idea of the real running costs of a practice and there is a serious lack of financial awareness. And there is a real difference in running costs. In London your building may cost $€ 100 \mathrm{k}-$ in Hull it could be $5 \mathrm{k}$. A nurse will cost $£ 20 \mathrm{k}$ in London whereas in Hull it may only be $8 \mathrm{k}$.'

Julian Perry turns to the patients again and their perception of practices.
'Image -well this is significantly more important now. We are living in a consumer-aware society. People will have to raise their game. It'll put some practices on the run.' He gives an example of 'raising the game'.

'We used to have Wimpy bars with plastic tables - these days the ambience is different, but' he reflects sadly 'they don't do knickerbocker glories any more!'

'Dentistry isn't a cottage industry, it's a cottage profession.' He feels dentists could learn much from the dental trade. 'The dental trade is more sophisticated than the profession. They have embraced change and technology far more so than the profession.'

'Quality standards such as Investors in People are important.' Ora Dental Group is the only dental body corporate to have achieved this standard. 'It's important to us that we meet them, and important to

\section{'Birmingham has the}

\section{same business training as}

it did 20 years ago when I

\section{was an undergraduate.}

\section{Dental schools should be}

\section{teaching people to be \\ fiscally aware.'}

patients that we have that commitment. It'll be 100 years before the profession realises that it's significant. The problem is that each individual dentist thinks that they're the best and provide the best level of care.'
He expands his theme of image and care. 'Care of our customers is essential. I don't mean patients - that implies sick, ill, hospital. Dental consumers aren't ill, they are customers. Customers are more aware of what they feel is the right environment and level of care. People have no idea of what really happens in their mouth, but that's what dentists like to concentrate on.'

It is at this point that I find out why Julian Perry set off a fire alarm. Perhaps he is so acutely aware of patients/customers because of this incident, when as a customer he feels he was treated so inappropriately. A few years ago, one of his children was ill, and with his clinical background he suspected meningitis. As many parents would, he took the child straight to hospital, explained the situation to the receptionist, and was told 'whilst she was filing her nails - I remember that vividly - that I had to be referred by my GP. I was so frustrated at not being listened to that I did the only thing I could to get people's attention. I set off the fire alarm. And that did it. People started running in from all over the place. Then I said 'NOW will you listen to me? It's a good thing they did because yes, my daughter did have meningitis.'

Standards of care are indeed something of a mission for Julian Perry, and he finishes with what sounds very much like a warning. 'In five years, unless government aggressively embraces issues like clinical governance, audit and quality, and increases the number of inspections the level of care delivered to patients will go down. All of this must also apply to private patients as well. We must start with the end user; there can be no compromise as far as the patient is concerned.'

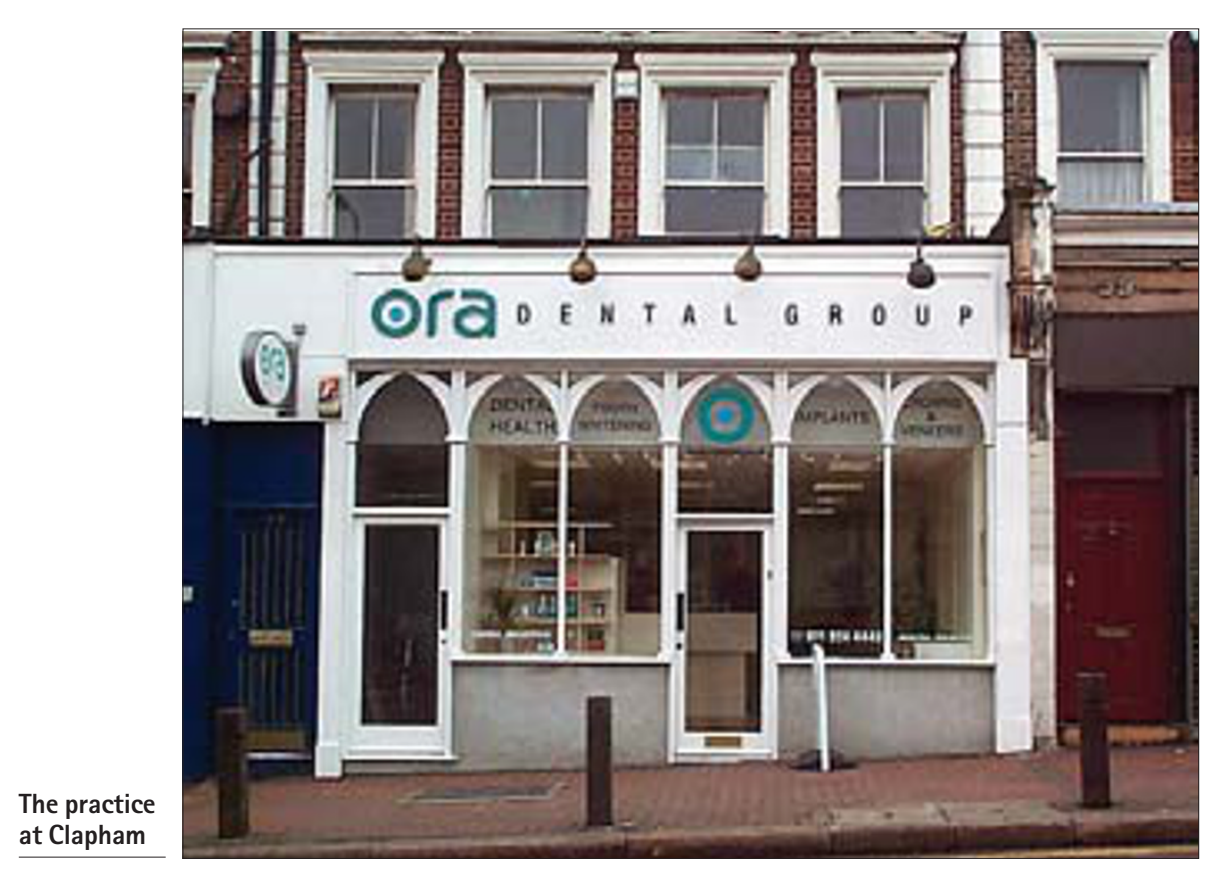

